\title{
Research on the Arrangement of Dew Point Temperature Detectors of Capillary Plane Radiation Air-Conditioning
}

\author{
Xuelai Liu, Jie Wu \\ School of Thermal Energy Engineering, Shandong Jianzhu University, Jinan, China \\ Email: wujie128128@163.com
}

Received December 2013

\begin{abstract}
Based on analysis of the reason and process of condensation on ceiling radiant cooling panels, two kinds of arrangement of detectors are put forward. The physical model is established, the results show that detectors are arranged as the form of triangle is more suitable. It can not only satisfy the use requirement but also it is economical and practical. Finally we can conclude that the inlet water temperature $0.5^{\circ} \mathrm{C}$ higher than dew point temperature is safe and reliable.
\end{abstract}

Keywords

Capillary Plane Radiation Air-Conditioning; Dew Point Temperature Detectors; Arrangement

\section{Introduction}

The reason for capillary radiation air conditioning condensation is ceiling radiant cooling panels surface temperature lower than the room air dew point temperature, the indoor wet air meet the ceiling radiant cooling panels surface cause condensation. The first reason for this phenomenon is that the supply and return water temperature of the cooling panels surfer is too low, the indoor relative humidity is too high, the water vapor near the surface of the ceiling radiant cooling panels condenses into water droplets. The second reason is that the air on the ceiling radiant cooling panels surface does not flow, the wind circulation of the air circulation device is hard to reach, it condenses easily because of the low temperature [1].

The condensation of the capillary radiation air conditioning not only affects the appearance beautifully, but also affects the cooling effect. Water is produced by condensation, which can damage the capillary radiation air conditioning ceiling radiant cooling panels surface, lead to bacterial growth, adsorption of dust and so on, make indoor sanitation poor.

In order to avoid the capillary surface condensation, cooling panels surface temperature must be higher than the indoor dew-point temperature [2]. The accuracy of the indoor dew point temperature is directly affected by the arrangement of dew point temperature detectors, so the problem needs to be studied. 


\section{Computing Models}

\subsection{The Basic Model}

The experiment room shapes and sizes, 10 meters long, 6 meters wide, 3.6 meters high, 10 capillary radiation air radiant panels are installed on the roof of the experiment room. Each of the radiant panel area is $2.5 \mathrm{~m}^{2}$. The size and the location of the radiant panels are shown in Figure 1.

\subsection{Measurement Parameters}

The inlet and outlet water temperature of the capillary radiation air conditioning: temperature detectors are arranged in the center of the water pipe.

The indoor temperature and humidity: detectors are arranged $0.1 \mathrm{~m}$ above the surface of the cooling panels.

The outdoor temperature and humidity: detectors are arranged outdoors.

The cooling ceiling surface temperature: detectors are arranged in the intermediate position of the cooling ceiling.

The top space of the cooling ceiling temperature: detectors are arranged on the cooling ceiling's top space.

The water flow of the cooling panels: measured with a rotameter [3].

\section{The Arrangement of Dew Point Temperature Detectors}

Dew point temperature detector is a fairly expensive device, and its arrangement directly affects the accuracy of the indoor dew point temperature, in the case to meet design specification we should reduce the detectors number as far as possible, arrange the detectors most reasonable. That is to say, detectors are arranged in an area, their detection zone should cover all the area, at the same time each detector's repeat detection area as little as possible.

Dew point temperature detectors are arranged according to their protection area, each dew point temperature detector protection area and protection radius is influenced by the height of the room slope of the housetop detectors sensitivity three main factors.

\subsection{Dew Point Temperature Detectors Are Arranged as the Form of Square}

Each adjacent dew point temperature detector is arranged as square, the detectors are arranged in the center of the circles shown in Figure 2. Obviously, when the neighboring four detectors respectively to do circles with their detection radius $\mathrm{R}$. If the detect radius is $1.5 \mathrm{~m}$, then the separation distance of the detectors is $2.1 \mathrm{~m}$, we can take an integer $2 \mathrm{~m}$. Dew point temperature detectors are arranged according to the form of square is shown in Figure 3.

\subsection{Dew Point Temperature Detectors Are Arranged as the Form of Triangle}

There is also a regular triangle arrangement, the detectors are arranged in the center of the circles shown in Figure 4. Obviously, when the neighboring three detectors respectively to do circles with their detection radius R.

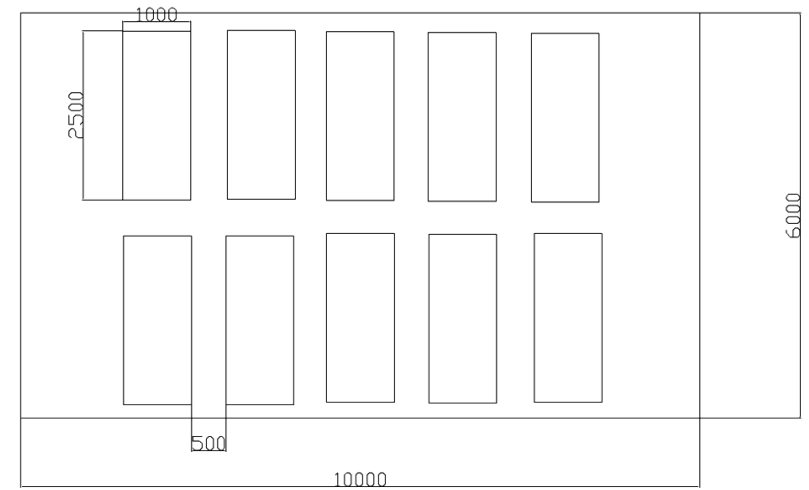

Figure 1. The size and the location of the radiant panels. 


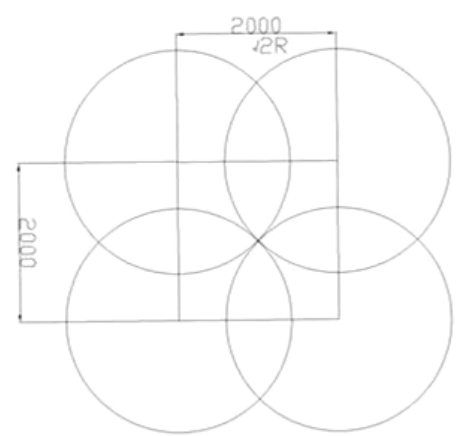

Figure 2. Detectors are square arranged.

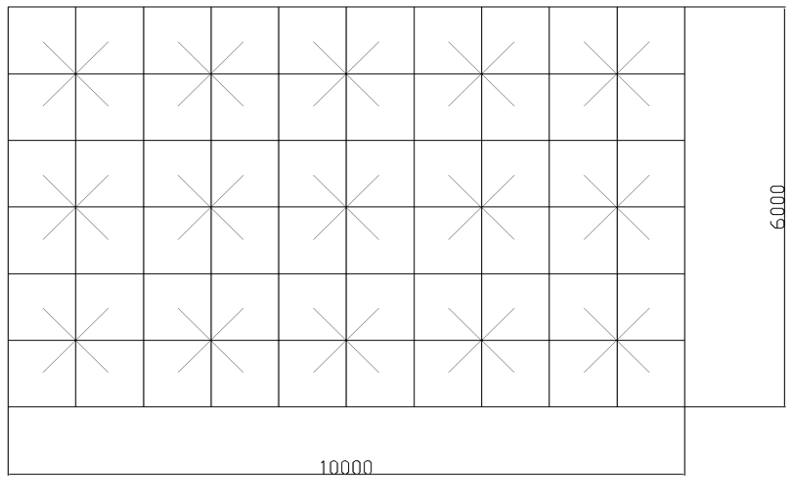

Figure3. The arrangement of detectors.

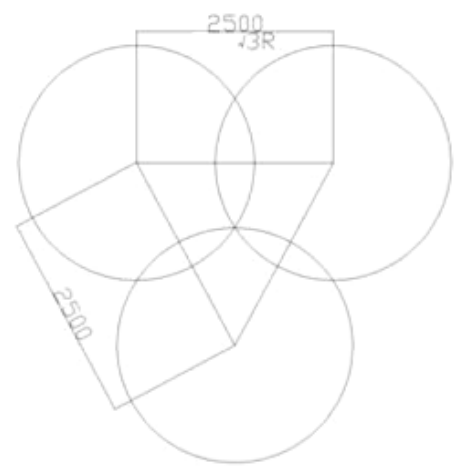

Figure 4. Detectors are square arranged.

If the detect radius is $1.5 \mathrm{~m}$, then the separation distance of the detectors is $2.5 \mathrm{~m}$. Dew point temperature detectors are arranged according to the form of triangle is shown in Figure 5.

\subsection{The Comparison of Two Kinds of Dew Point Temperature Detector Arrangement}

To compare Figures $\mathbf{3}$ and 5, we can find that detectors are arranged as the form of triangle is more suitable. This way can not only satisfy the requirement specification, but also make the repeat detection range less than the square arrangement, it is more economic.

\section{Results Analysis}

\subsection{To Compare the Dew Point Temperature of Cooling Panels Surface and Workspace $(1.5 \mathrm{~m})$}

Because we usually pay more attention to the temperature and humidity of the people active area $(1.5 \mathrm{~m})$, in the 


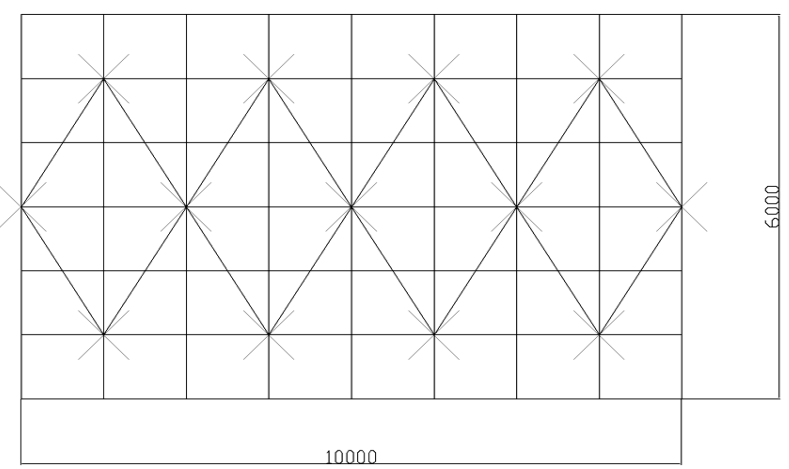

Figure 5. The arrangement of detectors.

past people through research the temperature of the active area to prevent dew. But in fact the temperature change on the vertical space within a building, this is because of the different vertical air density and vertical air flow, so the dew point temperature is different between the ceiling radiant cooling panels surfer and the people active area .If arrange the dew point temperature detectors in the people active area, the result will lack of precision. In order to better study the cooling panels dew problem, through compare the temperature and relative humidity near the surface of cooling panels and the active area. This paper defined distance $0.1 \mathrm{~m}$ is the surface of cooling panels. The calculate formula is shown as (1). The calculation results are shown in Figure 6.

$$
\mathrm{t}=-35.28896-2.03222 \operatorname{Inp}+1.17025(\operatorname{Inp})^{2}
$$

t Dew point temperature, ${ }^{\circ} \mathrm{C}$; $\mathrm{p}$ Water vapor partial pressure, pa. [4].

Analysis Figure 6 shows that the dew point temperature of the active area is $0.8^{\circ} \mathrm{C}$ higher than the ceiling radiant cooling panels surface.

\subsection{To Determine the Inlet Water Temperature}

Through the above analysis, detectors are arranged according to the form of triangle is more suitable for capillary plane radiation air-conditioning. So we arrange the detectors in the form of triangle, explore the relationship between the condensation critical condition on radiant cooling panels and inlet water temperature.

The air temperature and relative humidity of $0.1 \mathrm{~m}$ above the surface of ceiling radiant cooling panels to be measured, Check the enthalpy wet table to obtain dew point temperature, the dew point temperature and inlet water temperature of the capillary plane radiation air-conditioning to be compared. Conclusion can be obtained from Figure 7 that the design standard of the inlet water temperature to be set up $0.5^{\circ} \mathrm{C}$ [5] higher than the dew point temperature of the surface of ceiling radiant cooling panels is safe.

\subsection{The Relationship between Cooling Capacity and the Inlet Water Temperature}

The inlet water temperature of capillary plane radiation air-conditioning cooling capacity is set to $15^{\circ} \mathrm{C}, 16^{\circ} \mathrm{C}$, $17^{\circ} \mathrm{C}, 18^{\circ} \mathrm{C}, 19^{\circ} \mathrm{C}$ and $20^{\circ} \mathrm{C}$, set indoor temperature to $27^{\circ} \mathrm{C}$.

$$
Q_{C}=h_{c}\left(t_{A}-t_{B}\right) A
$$

Qc cooling capacity, $\mathrm{W} ; h_{c}$ surface coefficient of heat transfer, $\mathrm{W} /\left(\mathrm{m}^{2}{ }^{\circ} \mathrm{C}\right)$, here take3.5; A radiant panel surface area, $\mathrm{m}^{2}, A=25 \mathrm{~m}^{2}$ [6]. The results are shown in Figure 8.

From the Figure 8 we can see with the increase of inlet water temperature, the capillary plane radiation air-conditioning cooling capacity will reduce. So it is important to choose a suitable inlet water temperature, if the inlet temperature is lower than the dew point temperature, it will produce a condensation phenomenon. If the inlet temperature is too high, the capillary plane radiation air-conditioning cooling capacity will reduce, affecting the cooling effect of air conditioning room.

\section{Conclusion}

Detectors are arranged as the form of triangle is more suitable. This way can not only satisfy the requirement 


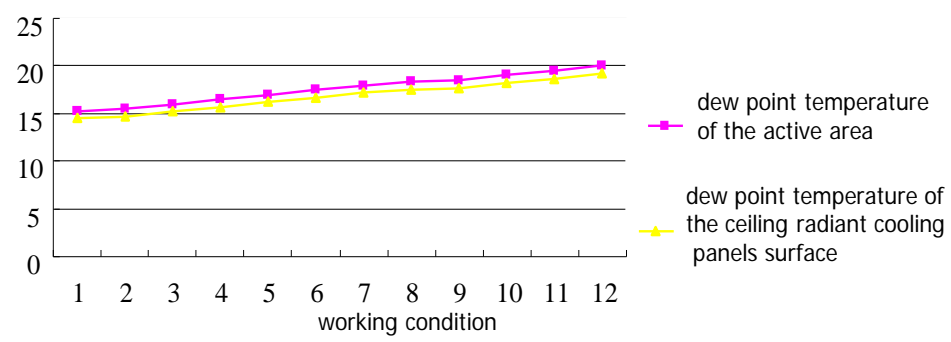

Figure 6. The dew point temperature.

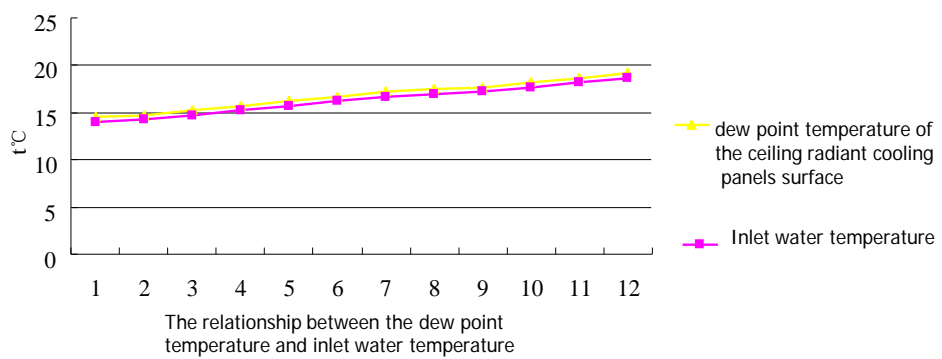

Figure 7. The relationship between the dew point temperature and inlet water temperature.

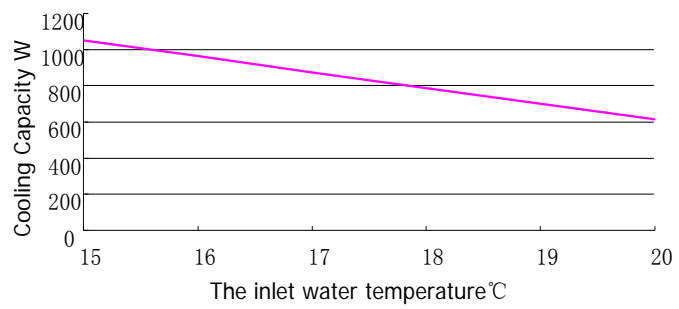

Figure 8. The inlet water temperature ${ }^{\circ} \mathrm{C}$.

specification, but also make the repeat detection range less than the square arrangement, it is more economic. The inlet water temperature to be set up $0.5^{\circ} \mathrm{C}$ higher than the dew point temperature is safe. At the same time the inlet water temperature can't be too high, because the capillary plane radiation air-conditioning cooling capacity will reduce with the increase of inlet water temperature. When indoor design temperature is $26^{\circ} \mathrm{C}$ to $28^{\circ} \mathrm{C}$, relative humidity is $40 \%-60 \%$, the dew point temperature is $14.5^{\circ} \mathrm{C}$ to $19.5^{\circ} \mathrm{C}$, so the inlet water temperature can be set as $15^{\circ} \mathrm{C}$ to $20^{\circ} \mathrm{C}$ [7-9].

\section{References}

[1] Bu, W.F., Wang, S.H., Shang, C.G. and Cao, Z.Q. (2001) Experimental Study of Cooling Ceiling System. Building Energy \& Environment, 3, 7-11.

[2] Zhang, L., Liu, X.H. and Jiang, Y. (2011) Experiment and Performance Analysis on Convection Strengthened Radiant Panel. Journal of HV\&AC, 41, 38-41.

[3] Ma. Y.-Q., Liu, X.-L., Li., Y.-A., et al. (2007) An Analysis of Condensation Process on Ceiling Radiant Cooling Panels. Journal of Shandong Jianzhu University, 22, 537-540.

[4] Sun, J.J. (2008) Research on Dynamic Simulation and Control System of Capillary Plane Radiation Air-Conditioning . Shandong Jianzhu University Academic Dissertation.

[5] Xue, H.X. (2009) Research on Comfort and Airflow in Rooms with Capillary Air-Conditioning Systems. Shandong Jianzhu University Academic Dissertation.

[6] Huang, Y.Y. and Zhang, L. (2003) Dehumidification for Floor Cooling. Journal of HV\&AC, 33, 47-51.

[7] Liu, S., Liu, X.H. and Jiang, Y. (2010) Dedicated Outdoor Air System in the THIC Air Conditioning System (1): Calculation of Space Moisture Load. Journal of HV\&AC, 40, 80-84. 
[8] Olesen, B.W. (1997) Possibilities and Limitations of Radiant Floor Cooling. ASHRAE Transactions, 103, 42-48.

[9] Olesen, B.W. and Michel, E. (2000) Heat Exchange Coefficient between Floor Surface and Space by Floor Cooling - Theory or a Question of Definition. ASHRAE Transactions, 106, 684-694. 